Vol. 5(1), pp. 1-6, May 2014

DOI: $10.5897 /$ J CEMS2014.0172

Artic le Number. D07831944426

ISSN 2141-6605

Copyright (c) 2014

Author(s) retain the copyright of this artic le

http://www.academic joumals.org/J CEMS
Journal of Chemical Engineering and Materials

Science

\title{
Characterization of palm kernel shell for materials reinforcement and water treatment
}

\author{
Edmund C. Okoroigwe ${ }^{1 *}$, Christopher M. Saffron ${ }^{2}$ and Pascal D. Kamdem ${ }^{3}$ \\ ${ }^{1}$ National Centre for Energy Research and Development, University of Nigeria, Nsukka. Enugu State, Nigeria. \\ ${ }^{2}$ Department of Biosystems and Agricultural Engineering, Michigan State University, East Lansing, USA. \\ ${ }^{3}$ Department of Packaging, Michigan State University, East Lansing, USA.
}

Received 13 January, 2014; Accepted 29 April, 2014

\begin{abstract}
As developing nations strive for economic sustainability, effort is geared towards exploiting biomass materials that could have alternative uses to their conventional low valued uses in order to achieve this goal. It is because of this that palm kernel shell, a byproduct of oil palm processing, is characterized for its application in construction and water treatment industries. The materials physical and chemical properties determined using standard methods show that it can find useful application in light weight construction as material filler and as sorbent material for industrial water treatment. The results of the x-ray photo spectrometry (XPS) and x-ray diffraction (XRD) reveal that the palm kernel shell (PKS) contains surface elements, morphology and crystalline qualities well required of material fillers in construction and adsorption industries. These can add to the market values of palm kernel shell as against its direct combustion and wastage of the material at oil palm processing mills.
\end{abstract}

Key words: Oil palm kernel shell, characterization, adsorbent, x-ray diffraction, micro porosity.

\section{INTRODUCTION}

In Indonesia, Malaysia and several West African countries, oil palm is commercially cultivated in plantations where trees are grown on a 25 to 30 year rotation followed by removal and replanting (Durst et al., 2004). In Nigeria, oil palm is an important tree because of the value of the crude palm oil, fronds, stems and leaves. Because of the magnitude of this industry, several residues are co-produced with palm oil. These include: the empty fruit bunch (EFB), palm fruit fiber (PFF), palm oil mill effluent (POME) and palm kernel shell (PKS). Whereas oil palm is chiefly cultivated for palm oil (PO) and palm kernel oil (PKO), the PKS (as residue) has been regarded as 'waste' from palm oil processing by Obeng et al. (1997), Lartey et al. (1999) and Ibhadode and Dagwa, (2008). It has been shown that approximately 15 to 18 tonnes of fresh fruit bunches are produced per hectare per year and PKS comprises about $64 \%$ of the bunch mass (Obisesan, 2004; Adewumi, 2009). In the developing world, waste PKS is either burned to supply energy at palm oil mills or left in piles to compost.

Many of the residues of oil palm harvesting and processing are valued for various applications. PKS has been laid on roads to improve vehicular traction

*Corresponding a uthor. E-mail: edmund.okoroigwe@unn.edu.ng

Author(s) a gree that this article rema in permanently open access under the terms of the Creative Commons Attribution License 4.0 Intemational Lic ense 
along plantation farms where there are no tarred roads. In a few communities, women have sold PKS as a source of heat for cooking; though much accumulates in piles when more is produced than utilized. PKS is commonly used in combustion processes, especially at oil mills as boiler fuel to generate heat and electricity (Yusoff, 2006) although PKS alone is not well regarded as a fuel due in part to smoke emissions (Yusoff, 2006; Walubengo, 1989). As a result, it is often combined with wood fuels, like sawdust or wood, to improve the calorific value of the biomass feed to the boiler (Kuti, 2007). Though its combustion value is substantial, the process of burning PKS releases significant volatiles and particulates which pose pre-ignition and pollution concerns. Instead of combusting PKS for energy, alternative products like concrete filler for infrastructure materials and bio-carbon for water treatment have been considered to establish new markets for this resource.

One of such options is production of activated carbon from PKS. Ogedengbe (1985) investigated the use of both charred and non-charred PKS for filtering effluent from sedimentation tanks of a water treatment plant. A dual media filtration unit composed of charred PKS and fine sand resulted in long filtration cycles and good water quality. The effluent from non-charred PKS beds also reduced the turbity of the effluent except that the water had the odor and taste of palm nuts. As with other forms of activated carbon, the use of PKS for water treatment depends upon its surface composition and chemical functionality. Characterization of PKS is needed to assess its applicability for treating a wide range of wastewaters.

Physically, PKS is relatively dense when compared to other biomass varieties, which has positive implications for transporting it for processing. Its high porosity supports its use in water treatment, but because of residual oleic acid, pyrolysis should first be employed to create a biocarbon sorbent. Compositionally, PKS is high in lignin, hemicellulose and silica-containing ash, resulting in a material with a large heating value that is unfortunately prone to forming particulate matter upon combustion. As such, alternative use as filler in infrastructure materials is recommended to fully take advantage of the natural strength properties that this composition provides. Though conversion to energy at power plants with sufficient pollution abatement equipment downstream of combustion remains an option, several characteristics of PKS support its use as material filler and sorbent for water treatment, both of which are greatly needed by the developing nations of the world.

In addition to energy production and water treatment, PKS can serve as a filler to reduce the costs of building and road-making materials. For instance, Okafor (1988), Okpala (1990) and Alengaram et al. (2008) have independently worked on determining the potential of PKS as a concrete reinforcement agent. According to Okafor (1988) PKS can produce concrete with compressive strength not exceeding $30 \mathrm{MPa}$, but compares well with conventional aggregates such as granite for concrete grades of $25 \mathrm{MPa}$ and less. Similarly, Okpala (1990) has shown that PKS is suitable for lightweight structural applications, while PKS mixed with concrete shows good sound absorption capacity and low thermal conductivity. The mechanical properties, such as crack width, deflection, ultimate strength, concrete strain and steel strain of PKS concrete were compared with those of normal weight concrete by Alengaram et al. (2008). This work shows that even though the flexural strength of the PKS concrete was $15 \%$ lower than that of normal weight concrete, its compressive strength was 6 $\mathrm{MPa}$ more than the targeted $30 \mathrm{MPa}$. These results show that PKS can be used in light weight structures up to loads of $36 \mathrm{MPa}$.

Road-making is another application that can potentially benefit upon using PKS as material filler. It is recommended that for heavily trafficked roads, PKS can replace aggregates of stone dust and bitumen in 10\% blends with asphalt (Ndoke, 2006). Complete replacement of traditional aggregates is possible for lightly trafficked roads in rural settings. Even the partial displacement of bitumen will reduce the human and ecosystem toxicity levels associated with roadways, as bitumen contains polyaromatic hydrocarbons, several of which are known carcinogens. Though PKS is typically either burned or abandoned, the present study suggests its use as a valuable co-product water treatment and as filler for building and construction materials. The efficacy of PKS for the above applications, water treatment and materials reinforcement depends upon its composition and surface chemistry. Hence, there is need for a comprehensive characterization of PKS to assist in deciding amongst its possible applications. In this investigation, both compositional and surface characteristics of PKS are measured using analytical devices and established methods with the objective of informing potential users and marketers of its intrinsic value for sustainable economic development.

\section{MATERIALS AND METHODS}

Palm Kernel Shells used in this investigation were obtained from Nsukka urban where the mean annual rainfall of $1,981 \mathrm{~mm}$ (Anyadike, 1992) favors commercial oil palm production in the area, as is common within Southern Nigeria. The sample used was a mixture of palm kernel shells from Dura and Pisifera species since the varieties are not usually sorted during palm oil processing. Prior to experimentation, the PKS were sun dried in open air at ambient temperature of $31^{\circ} \mathrm{C}$. They were transferred to cellophane bags and sealed. They were further crushed using Willey Milling Machine to a particle size of $425 \mu \mathrm{m}$ passing sieve 40 . The moisture content was determined using ASTM D4442-92 standard at $105^{\circ} \mathrm{C}$ while ASTM D3174-04 was used for ash content determination at $950^{\circ} \mathrm{C}$. X-ray diffraction (XRD) was used to measure PKS crystalinity and to reveal the compositional structure of the sample. XRD patterns were obtained on a Rigaku Rotaflex 200B diffractometer equipped with copper $\mathrm{Ka} \mathrm{X}$-ray radiation and a curved crystal graphite monochromator operating at $45 \mathrm{kV}$ and $100 \mathrm{~mA}$. 
Table 1. Bulk physical and chemical characteristics of palm kernel shell.

\begin{tabular}{|c|c|c|c|}
\hline \multirow{2}{*}{ Property } & \multirow{2}{*}{ Parameter } & \multicolumn{2}{|c|}{ Value } \\
\hline & & $\mathrm{Ar}$ & $\mathrm{db}$ \\
\hline \multirow{4}{*}{ Physical } & Moisture content (\%) & 6.11 & - \\
\hline & Ash content $(\%)$ & 8.68 & \\
\hline & ${ }^{*}$ Bulk density $\left(\mathrm{kg}-\mathrm{m}^{-3}\right)$ & 740 & 9.24 \\
\hline & ${ }^{*}$ Porosity $(\%)$ & 28 & 650 \\
\hline \multirow{6}{*}{ Chemical } & $\mathrm{C}(\%)$ & 46.75 & 49.79 \\
\hline & $\mathrm{H}(\%)$ & 5.92 & 5.58 \\
\hline & $\mathrm{O}(\%)$ & 37.97 & 34.66 \\
\hline & $\mathrm{N}(\%)$ & 0.68 & 0.72 \\
\hline & S (\%) & $<0.08$ & $<0.08$ \\
\hline & $\mathrm{Cl}(\mathrm{ppm})$ & 84 & 89 \\
\hline \multirow{3}{*}{$\begin{array}{l}\text { Structural } \\
\text { carbohydrates }\end{array}$} & Hemicellulose (\%) & \multicolumn{2}{|c|}{26.16} \\
\hline & Cellulose $(\%)$ & \multicolumn{2}{|c|}{6.92} \\
\hline & Lignin (\%) & \multicolumn{2}{|c|}{53.85} \\
\hline
\end{tabular}

ar (as received), db (dry basis), *(Ndoke, 2006).

X-ray photoelectron spectroscopy (XPS) is used to determine the elemental composition of the PKS surface. A Perkin Elmer Phi 5400 ESCA system was used for this analysis with magnesium Ka X-ray source. Atomic concentrations were determined using previously determined sensitivity factors. All peaks were referenced to the signature $\mathrm{C} 1 \mathrm{~s}$ peak for adventitious carbon at $284.6 \mathrm{eV}$. The structural carbohydrates and lignin were determined using the twostep, $72 \%$ sulphuric, acid hydrolysis method developed by the National Renewable Energy Laboratory (NREL/TP-510-42618), 2008.

The anatomical structure of PKS was observed using a JEOL JSM-6400V (lanthanum hexaboride electron emitter) scanning electron microscope, after coating PKS samples with osmium $(\sim 10$ $\mathrm{nm}$ thickness) in an NEOC-AT osmium coater. The digital images were acquired using Analysis Pro software version 3.2 (Olympus Soft Imaging Solution Corp., Münster, Germany).

\section{RESULTS AND DISCUSSION}

Table 1 contains a compilation of several physical and chemical characteristics of the PKS sample that was used. From the table it can be shown that PKS has an appreciable bulk density for plant biomass, equal to 740 $\mathrm{kgm}^{-3}$ (wet) and $650 \mathrm{kgm}^{-3}$ (dry). This may be advantageous to PKS users, as greater bulk density corresponds to reduced hauling costs. Moisture contents between 6 and $9 \%$ are normal after equilibration with the laboratory environment. These characteristics compare to those of similar barrier tissues such as coconut shell (ECN, 2008).

Structurally, PKS is composed mainly of lignin and hemicellulose as measured by the method devised by NREL. PKS was found to be nearly $54 \%$ lignin, which is higher than other shell residues such as coconut shell
(ECN, 2008). This is similar to that obtained by Daud et al. (2004) as reported by Maedeh et al. (2011). The hemicellulose content is also consistent with shell residue material and the relatively large amount suggests that PKS could serve as a pentose sugar source provided that the high lignin content can be disrupted by pretreatment. Its structural properties support its use as low-cost filler for building and road making materials.

\section{X-ray powder diffraction (XRD)}

The results of XRD displayed in Figure 1 show three crystal peaks corresponding to d-4.34, d-4.19 and d-3.39. A peak at d-4.34 and $2 \theta$ equal to 20.6 is likely silicon oxide, which is a component of PKS. Oleic acid, identified at $\mathrm{d}-4.19$, is likely residue from palm oil and palm kernel oil. PKS is largely amorphous as its crystallinity is only $14.38 \%$, which is indicative of its high lignin and hemicellulose contents. This quality may be useful in application of PKS as material filler. Okafor (1988), Okpala (1990) and Alengaram (2008) have shown that moderate strength concrete can be formed using PKS as filler.

\section{X-ray photo spectrum (XPS)}

The XPS result (Table 2) and it's spectrum (Figure 2) show the presence of other elements such as aluminum, silicon, calcium and iron, on the surface of PKS samples. Although, these elements are in trace quantity when compared with carbon and oxygen, they play significant 


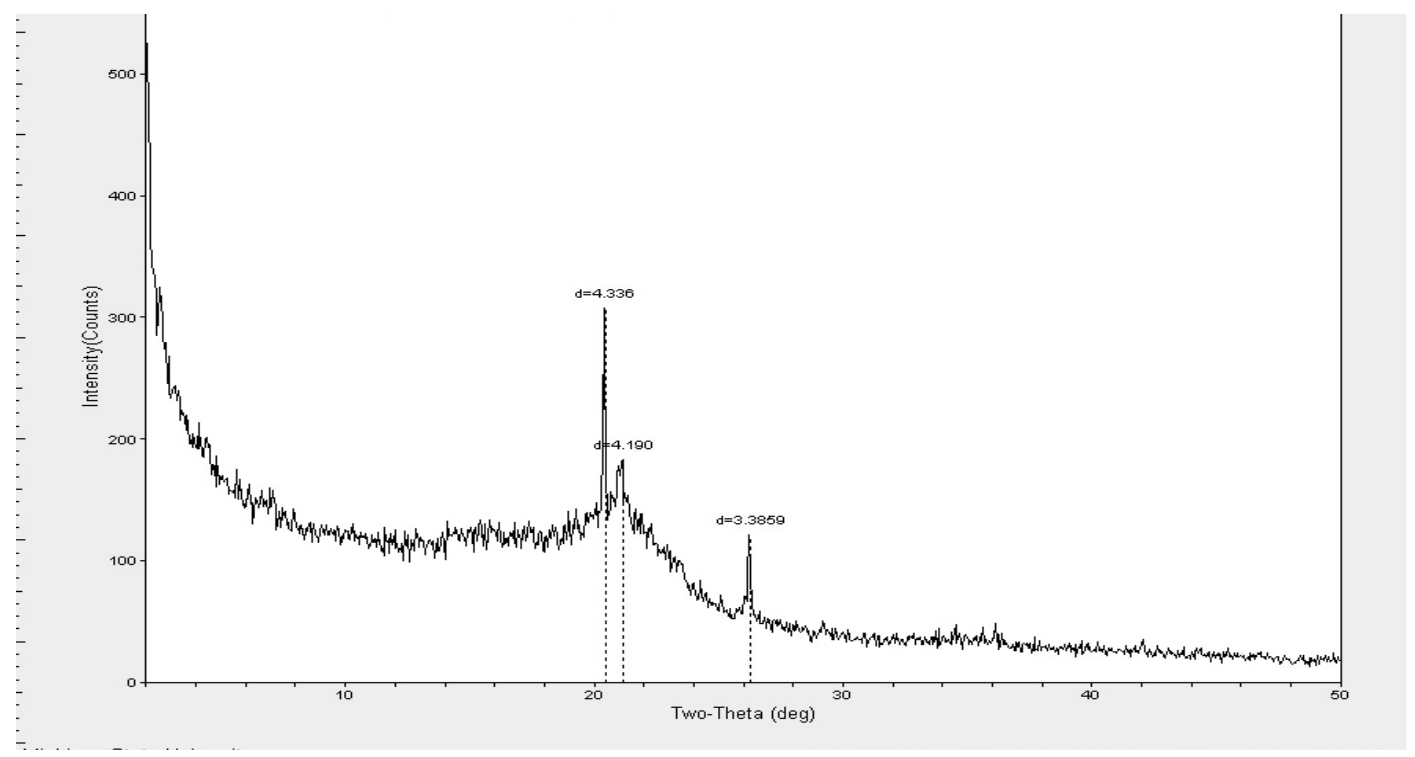

Figure 1. XRD of the palm kernel shell sample.

Table 2. The X-ray photoelectron atomic concentration table of palm kernel shell surface on mole basis showing the predominance of carbon and oxygen.

\begin{tabular}{ccccccc}
\hline C1s & N1s & O1s & Al2p & Si2p & Ca2p & Fe2p \\
\hline 75.52 & 0.90 & 20.96 & 0.98 & 1.17 & 0.20 & 0.27 \\
\hline
\end{tabular}

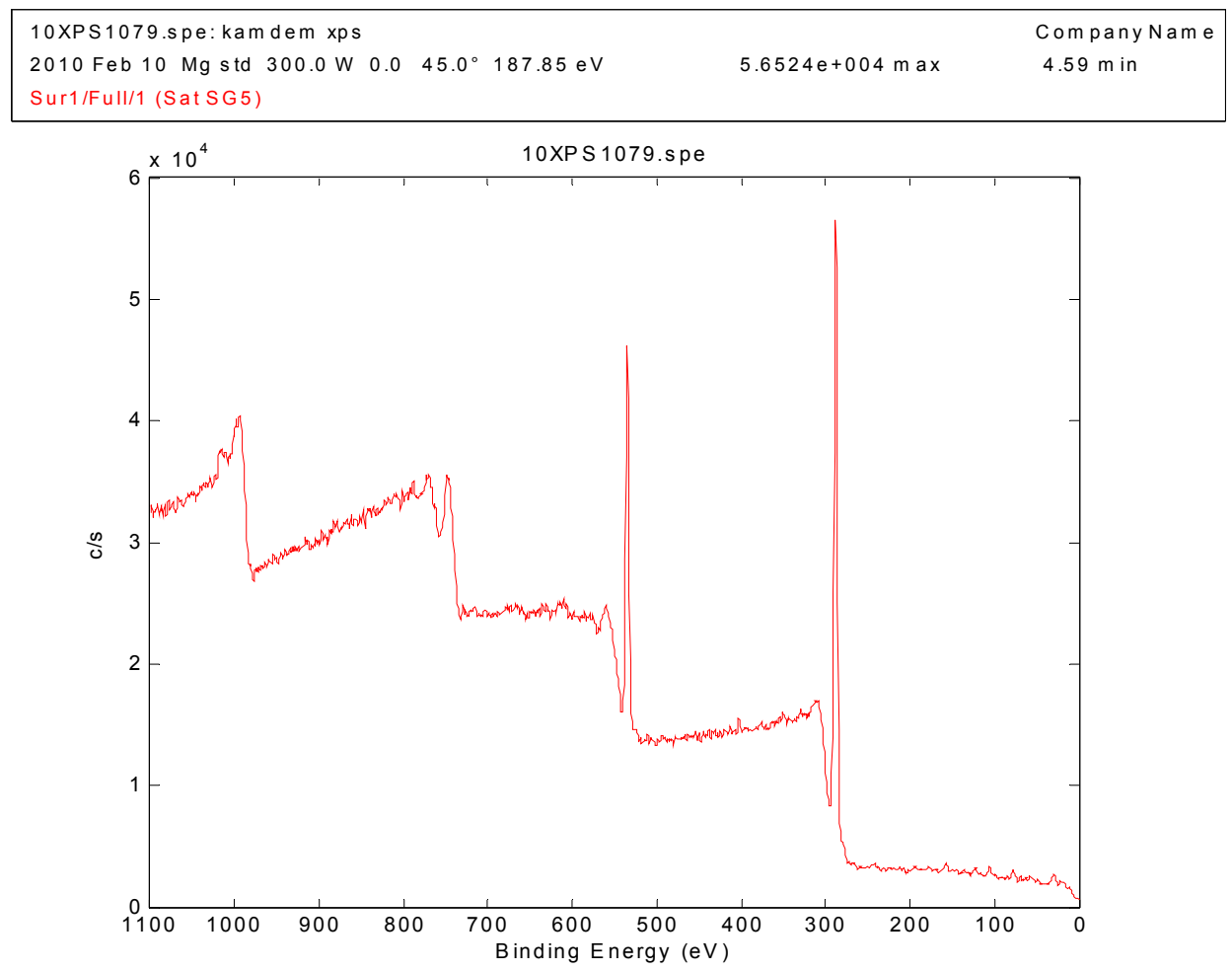

Figure 2. XPS spectrum of the palm kernel shell. 


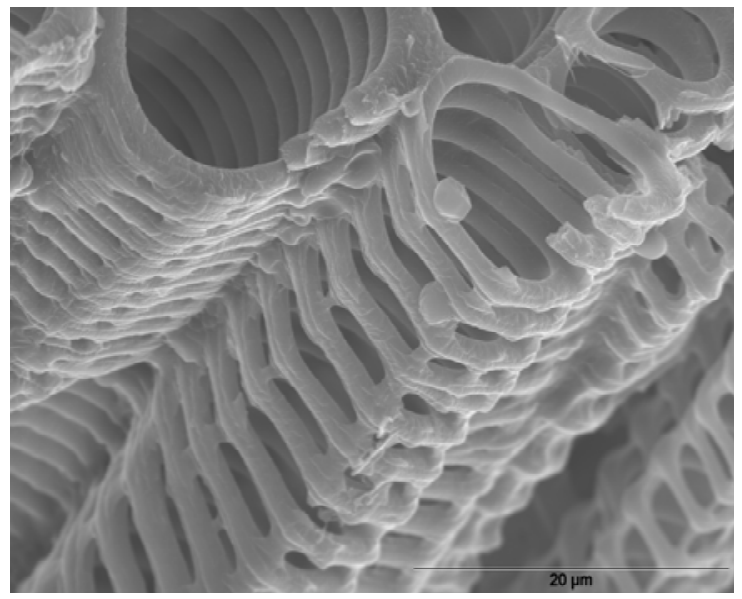

a) Scale : $20 \mu \mathrm{m}$

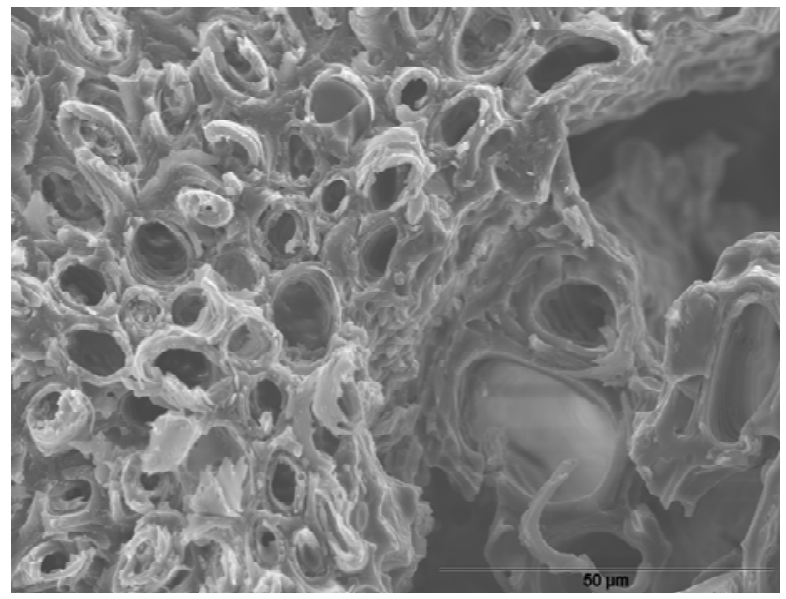

b) Scale : $50 \mu \mathrm{m}$

Figure 3. SEM images of the palm kernel shell showing the natural pores in the shell.

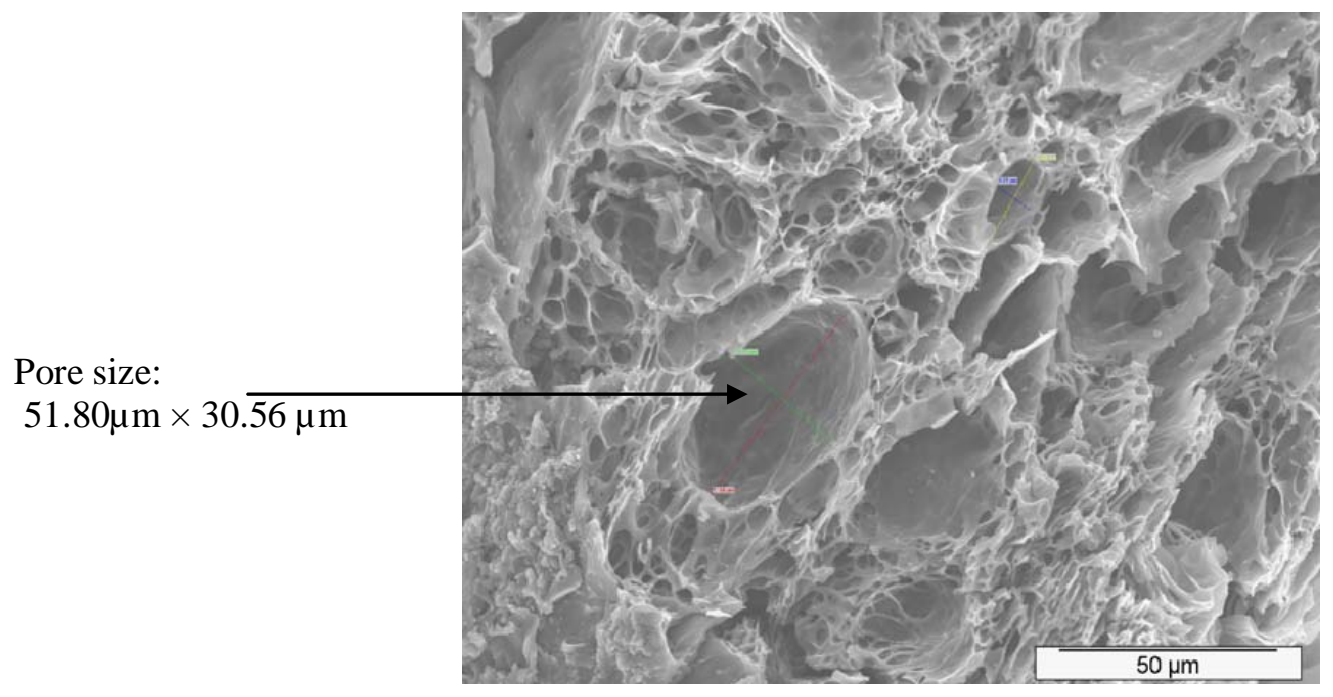

Figure 4. Scanning electron micrograph of palm kernel shell after pyrolysis showing the porosity of the resultant char.

role in presenting the sample good for material filler in construction industry. It is the presence of silicon that gives the sample its crystalline property as presented by the XRD spectrum (Figure 1).

\section{Scan electron microscopy}

Morphology and pore structure are important for expelling volatiles when subjected to thermochemical processes such as torrefaction, pyrolysis and gasification. The SEM images in Figure 3(a) and (b) reveal the porous and heterogenous structure of the heat-untreated palm kernel shell. These micrographs reveal the micro pores through which the kernel exchanged fluids with the surrounding mesocarp. Thus PKS has potential as a sorbent material. After pyrolysis, an increase in macro porosity is observed in the SEM image shown in Figure 4 which is consistent with Uzun et al. (2010) for heat-treated tea waste. Guerrero (2005) shows that macro porosity increases after pyrolysis. Macro pores give access to the inner surface of the particle, while micro pores, created during activation (Cookson, 1978) are responsible for the large surface area of the activated carbon (Lartey et al., 1999). The high porosity of PKS char suggests that water treatment should be considered as an application of this 
material. This has wide industrial applications in chemical, food and pharmaceutical industries as well as metal recovery and water treatment. Activated carbon is in high demand in African countries like Ghana (Lartey et al., 1999) and Nigeria (Adewumi, 2009) and the industry can create enormous job and business opportunities in communities where oil palm is produced.

\section{Conclusions}

Palm kernel shell is characterized for use as a sorbent in water treatment technology, as a filler material in the construction industry. PKS has utility for a wide range of applications as alternative to direct combustion. As a source of energy, PKS has an appreciable heating value but suffers from smoke production during combustion. Xray photoelectron spectroscopy reveals a higher carbonto-oxygen ratio on the surface than in the bulk solid, implying that PKS may serve as filler in hydrophobic materials or as a sorbent for moderately hydrophobic contaminants. Other characterization results also support the application of the biomass in both construction material filler and water treatment agent in the food and beverage industry.

\section{ACKNOWLEDGEMENTS}

Authors are grateful to US Department of State for Fulbright Grant 15094001 to Edmund Okoroigwe in 2009/2010 academic year through IIE New York. A portion of this work was funded by AgBioResearch at Michigan State University.

\section{Conflict of Interests}

The author(s) have not declared any conflict of interests.

\section{REFERENCES}

Adewumi IK (2009). Activated Carbon for water treatment in Nigeria: Problems and prospects, in: Yanful EK (Ed), appropriate technologies for environmental protection in the developing World. Netherlands: Springer. pp. 115-122.
Alengaram UJ, Jumaat MZ, Mahmud H (2008). Ductility behavior of reinforced palm kernel shell concrete beams. Eur. J. Sci. Res. 23:406-420.

Anyadike RNC (1992). Regional variations in fluctuations of seasonal rainfall over Nigeria. Theor. Appl. Climatol. 45:285-292.

Cookson JT (1978). Adsorption mechanisms: The chemistry of organic adsorption on activated carbon, in: Cherimisinoff PN, Ellerbusch F (Eds), Carbon Adsorption Handbook. Ann Arbor: Ann Arbor Science Publishers, pp. 241-279.

Daud WMAW, Ali WSW (2004). Comparison on pore development of activated carbon produced from palm shell and coconut shell. Bioresour. Technol. 93(1):63-69.

Durst PB, Killmann W, Brown C (2004). Asia's new woods. J. For. 102:46-53.

ECN Phyllis 2 databse (2008). The Composition of Biomass and Waste. (http://www.ecn.nl/phyllis/)

Guerrero M, Ruiz MP, Alzueta MU, Bilbao R, Millera A (2005). Pyrolysis of eucalyptus at different heating rates: studies of char characterization and oxidative reactivity. J. Anal. Appl. Pyrol.74:307314.

Ibhadode AOA, Dagwa IM (2008). Development of asbestos-free friction lining material from palm kernel shell. J. Braz. Soc. Mech. Sci. Eng. 30:166-173.

Kuti OA (2007). Impact of charred palm kernel shell on the calorific value of composite sawdust briquette. J. Eng. Appl. Sci. 2:62-65.

Lartey RB, Acquah F, Nketia KS (1999). Developing national capability for manufacture of activated carbon from agricultural wastes. The Ghana Engineer.

Maedeh M, Ghasem DN, Abdul RM (2011). Production of Carbon Molecular Sieves from Palm Shell through Carbon Deposition from Methane. Chem. Ind. Chem. Eng. Q. 17(4):525-533.

Ndoke PN (2006). Performance of palm kernel shells as a partial replacement for coarse aggregate in asphalt concrete. Leonardo Electronic J. Pract. Tech. pp. 145-152.

Obeng K, Ocran KAG, Anaba D (1997). Palm kernel shell as fuel for burning bricks. Build Res. Info. 25:131-136.

Obisesan IO (2004). Yield, the ultimate crop improvement. Inaugural Lecture Series No 168, Obafemi Awolowo University, Ile-Ife.

Ogedengbe $O$ (1985). Dual-media filtration with sand and palm kernel shells. Int. J. Dev. Technol. 3:251-260.

Okafor FO (1988). Palm kernel shell as a lightweight aggregate for concrete. Cem. Concr. Res. 18:901-910.

Okpala DC (1990). Palm kernel shell as a lightweight aggregate in concrete. Build Environ. 25:291-296.

Uzun BB, Apaydin-Varol E, Ates F, Ozbay N, Putun AE (2010). Synthetic fuel production from tea waste: Characterization of bio-oil and bio-char. Fuel. 89:176-184.

Walubengo D Ed (1989). Briquetting of biomass waste. Report of the Proceedings of the International Biomass Course held at Sagret Hotel, Nairobi, Kenya, June, 1989. Published by Kenya Energy and Environment Organizations in Nairobi, pp. 26-28.

Yusoff S (2006). Renewable energy from palm oil - innovation on effective utilization of waste. J. Clean Prod.14:87-93. 